\title{
Análise das condições ambientais em sistemas de alojamento 'freestall' para bovinos de leite
}

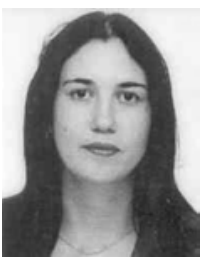

Silvia R. L. de Souza1, Irenilza A. Nääs ${ }^{2}$, Francine G. Marcheto³ ${ }^{3}$ Douglas D. Salgado ${ }^{4}$

\footnotetext{
1 Mestranda, FEAGRI/UNICAMP. CP 6011, CEP 13083-970. Campinas, SP. Fone: (019) 3788-1039. Fax: (019) 3788-1010. E-mail: silucas_souza@hotmail.com (Foto)

2 DECR/FEAGRI/UNICAMP- E-mail: irenilza@agr.unicamp.br

${ }^{3}$ Estudante de Engenheira Agrícola, E-mail: frangm@hotmail.com

${ }^{4}$ Estudante de Estatística, IMEC- UNICAMP-E-mail: overdoug@zipmail.com.br
}

Protocolo 157 - 29/10/2002 - Aprovado em 16/2/2004

\begin{abstract}
Resumo: No Brasil, em algumas regiões, as condições climáticas são desfavoráveis às raças leiteiras européias, devido às dificuldades de adaptação, fato que afeta diretamente o setor produtivo de leite e, com o desenvolvimento de novas tecnologias, torna-se imprescindível que o potencial genético seja evidenciado nos animais. Desta forma, o conhecimento das respostas da exposição das vacas em produção ao ambiente adequado, pode ter reflexo na produtividade leiteira. $O$ experimento foi realizado na Fazenda Paraíso no município de Santo Antônio do Jardim, SP, onde foram utilizadas 470 vacas em lactação distribuídas em 6 lotes e analisadas em dois períodos, que se estenderam de setembro a novembro de 2000 e de setembro a novembro de 2001, um sem climatização e outro com climatização, respectivamente. $O$ objetivo deste trabalho foi analisar o ambiente físico de instalações de bovinos de leite em sistema de 'free-stall' com base nos índices de conforto térmico (ITU) e (ITGU). Os resultados obtidos de ITU e ITGU médios, para o grupo com climatização, foram melhores quando comparados ao grupo sem climatização, e estiveram dentro das faixas consideradas satisfatórias para estes índices ambientais, concluindo-se que, tanto o ITU quanto o ITGU foram melhores para o grupo com equipamentos de climatização.
\end{abstract}

Palavras-chave: conforto térmico, índices do ambiente térmico

\section{Analysis of the ambient conditions in systems of freestall lodging for dairy cows}

\begin{abstract}
Brazilian climatic conditions are highly unfavorable for European dairy cows breeds due to the difficulties in adapting to thermal comfort, leading to direct losses in milk production. The development of new technologies is needed in order to permit a better expression of the animal's genetic potential. The knowledge of the dairy cows response to adequate environment may improve milk production. However, the misuse of unappropriate solutions of cooling equipment can lead to the increase in production costs. The experiment was carried out at the Paraíso Farm in the municipallity of Santo Antonio do Jardim, SP, where 470 cows in lactation were used distributed in 6 lots, and analyzed in two periods from September to November, 2000 (T1) and September to November, 2001 (T2), without climatization and with climatization, respectively. The objective of this research was to analyze the physical housing environment of dairy cows housed in free-stall system using the thermal comfort indexes (THI) and (WBGT). The obtained results of average THI and WBGT for the group (T2) with climatization was better when compared with the group (T1) without climatization. The conclusion was that both THI and WBGT were better and satisfactory for the group with cooling equipments.
\end{abstract}

Key words: thermal comfort, thermal environmental indexes, dairy cows

\section{INTRODUÇÃO}

O Brasil é o sexto maior produtor de leite do mundo e esta produção cresce a uma taxa anual de $4 \%$, superior à de todos os países que ocupam os primeiros lugares (Vilela, 2002). Contando com um rebanho de gado de leite em 1995 com aproximadamente 16,5 milhões de cabeças, constatou-se um aumento considerável em 2000, passando para 19,8 milhões. 
A maior parte do rebanho leiteiro está localizada nas regiões mais quentes do País e a quantidade de leite cru ou resfriado produzido entre os meses de janeiro e setembro de 2001 corresponde à produção de 9,6 mil litros de leite. Praticamente, toda a produção leiteira do Brasil provém de sistemas semiestabulados de criação (IBGE, 2001).

Métodos de manejo adequado do gado leiteiro poderão reverter em uma melhor produção do rebanho. Além dos sistemas adequados de exploração, as instalações também fazem parte da maximização da produção leiteira, sem contar com a genética, a nutrição e a sanidade animal.

Em busca de um desempenho melhor do rebanho, leva-se em consideração o clima em que os animais se encontram. Os elementos climáticos influenciam o desempenho animal e, desta maneira, deve-se atuar no sentido de minimizar seus efeitos, utilizando construções adequadas para abrigar esses animais. Além disso, no Brasil prevalecem as altas temperaturas associadas a altas umidades relativas.

Titto (1998) diz que muitas granjas leiteiras utilizam vacas de alto padrão genético para produção de leite e que esses animais possuem metabolismo elevado. A climatização é utilizada numa tentativa de diminuir os efeitos dos fatores ambientais limitantes à produção animal.

Estejam os animais abrigados ou não, eles sofrem os efeitos da radiação solar, cuja intensidade é determinada pela carga de radiação proveniente das redondezas. Se esses animais forem expostos, receberão cargas de radiação provenientes do sol, atmosfera, horizonte e do solo (com cobertura ou não); se, porém, abrigados, a carga de radiação incidente direta diminui, só que acrescidas das cargas da sombra gerada dos próprios materiais utilizados na confecção do abrigo onde a carga térmica radiante é menor (Baêta e Souza, 1997).

A maior restrição à produção zootécnica em países de clima quente encontra-se na própria dificuldade de que os animais foram geneticamente desenvolvidos e alojados em condições ou conceitos provenientes de climas mais amenos; daí a necessidade de instalações adaptadas com características construtivas que garantam o mínimo de conforto, permitindo ao animal abrigado desenvolver todo o seu potencial genético (Arcaro, 2000). Desta forma, o objetivo do presente trabalho foi analisar o ambiente térmico em instalações comerciais de bovinos de leite, sistema de 'freestall', com base nos índices térmicos ITU e ITGU.

\section{MATERIAL E MÉTODOS}

O presente trabalho foi desenvolvido na Fazenda Paraíso próximo à cidade de Santo Antônio do Jardim, Estado de São Paulo, cuja latitude é $22,14^{\circ} \mathrm{S}$ longitude de $46,74^{\circ} \mathrm{W}$ e altitude $750 \mathrm{~m}$. A temperatura máxima $33^{\circ} \mathrm{C}$ e mínima $22^{\circ} \mathrm{C}$. A umidade relativa média foi de $75 \%$.

Foram utilizadas 470 vacas em lactação distribuídas em 6 lotes nos dois períodos constituídos por primíparas, multíparas e pósparto, com peso vivo estimado de $700 \mathrm{~kg}$. Ultilizaram-se no experimento todos os lotes, que contavam com características genéticas e morfológicas homogêneas da raça Holandesa, de alta produção e puros por cruza, alojadas em sistema de exploração comercial.
Os dados foram registrados durante os meses de setembro à novembro de 2000 e setembro à novembro de 2001, correspondentes a 68 dias de experimento para cada ano.

As vacas receberam a mesma dieta alimentar de acordo com o manejo da fazenda, tais como, silagem de milho, farelo de soja, grão de milho moído e minerais, que foram fornecidos de maneira a atender todas às exigências nutricionais de acordo com o NRC, com porcentagem de materia seca igual a $45 \%$ para manutenção e produção de leite.

Devido à ausência de um posto climatológico que possibilitasse a coleta dos dados externos no ano de 2000, utilizaram-se os dados regionais. No período de 2001 foram instalados termômetros de globo negro e datallogers em uma mini-estação meteorológica localizada no meio do pasto, próximo às instalações, para coleta de dados.

Os dados da avaliação do ambiente do 'freestall' foram coletados nos seguinte horários: às 7:00 h. para temperatura mínima (Tmin) e às 14:00 h. temperatura máxima (Tmáx) e temperatura de globo máxima (Tgmáx). A umidade relativa média foi medida nos mesmos horários.

Empregaram-se 2 galpões de 'freestall' com uma distância de aproximadamente $20 \mathrm{~m}$, ambos orientados no sentido leste-oeste. Em cada galpão continha 4 grupos de camas com 56 divisões. $\mathrm{O}$ comprimento de cada galpão era de $85 \mathrm{~m}$ por $29,4 \mathrm{~m}$ de largura e o pé- direito de $3,6 \mathrm{~m}$. Os galpões eram totalmente abertos nas laterais com piso de concreto ranhurado para facilitar o escoamento das águas residuárias. A cobertura, apoiada sobre pilares de concreto pré-moldado, era de telhas metálicas, de duas águas e possuía lanternim.

Os equipamentos de climatização (ventiladores e nebulizadores) foram instalados no interior dos galpões sendo que os ventiladores foram colocados a uma altura de $3,0 \mathrm{~m}$ e alternados nos pilares internos dos galpões para que estes ficassem mais próximos dos animais. O total de ventiladores foi de $32 \mathrm{em}$ cada galpão, com potência de $0,5 \mathrm{CV}$, com uma hélice de 4 pás de $40 \mathrm{~cm}$ e uma vazão de $150 \mathrm{~mL} \mathrm{~min}^{-1}$. O sistema de ventilação era acionado quando a temperatura interna atingia $25^{\circ} \mathrm{C}$.

A nebulização era composta por 4 bicos de nebulizadores acoplados aos ventiladores com uma vazão de $600 \mathrm{~mL} \mathrm{~min}{ }^{-1}$. Os nebulizadores eram acionados por um termostato de bulbo úmido, quando a temperatura interna atingia $27^{\circ} \mathrm{C}$, ligando e desligando a cada 60 segundos, bem como quando a umidade relativa se encontrava a $85 \%$. A distribuição de água até os bicos nas pás dos ventiladores foi realizada através de um cano flexível preto de 6,5 milímetros (Figura 1).

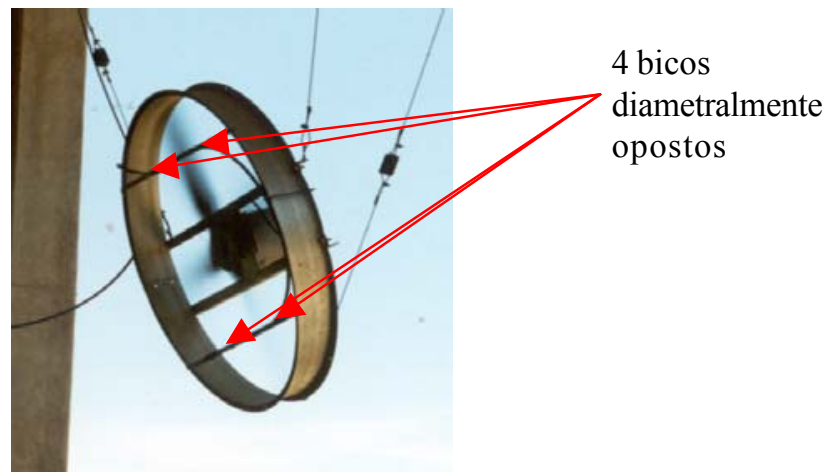

Figura 1. Detalhe dos nebulizadores acoplados aos ventiladores 
Foram calculados os índices de conforto térmico; indice de temperatura e umidade (ITU) e o indice de temperatura de globo e umidade (ITGU). O ITU foi calculado através da fórmula recomendada por Baccari et al. (1983).

$$
\mathrm{ITU}=\mathrm{Ts}+0,36 \mathrm{To}+41,2
$$

Ts - temperatura do termômetro de bulbo seco, ${ }^{\circ} \mathrm{C}$

To - temperatura do ponto de orvalho, ${ }^{\circ} \mathrm{C}$

O ITGU foi calculado através da fórmula desenvolvida por Buffington et al. (1981).

$$
\mathrm{ITGU}=\mathrm{Tg}+0,36 \mathrm{To}+41,5
$$

$\mathrm{Tg}$ - temperatura do termômetro de globo negro, ${ }^{\circ} \mathrm{C}$

To - temperatura do ponto de orvalho, ${ }^{\circ} \mathrm{C}$

Para a obtenção da temperatura de ponto de orvalho (to) foi usado o software Psicard ${ }^{\circledR}$ adaptado para o Excel ${ }^{\circledR}$.

Avaliaram-se estatisticamente dois tratamentos com vacas alojadas em estábulo 'freestall', como segue: sem recursos de climatização: período experimental (setembro, outubro e novembro/ 2000) - T1; com nebulizadores acoplados a ventiladores (setembro, outubro e novembro/2001).

Foram utilizadas vacas da raça Holandesa preto e branca, com características genéticas e morfológicas homogêneas e puro por cruza.

Os resultados foram submetidos a uma análise de variância para determinar a significância das variáveis nos diferentes tratamentos, utilizando-se o software Minitab ${ }^{\circledR}$. Foram realizados testes não paramétricos para comparação de medianas a fim de se determinar o intervalo de confiança.

\section{RESULTADOS E DISCUSSÃO}

Os dados dos dois períodos foram analisados estatisticamente e os resultados indicaram que as temperaturas máximas dos dois períodos não apresentaram diferenças significativas (Figura 2).

De acordo com as análises estatísticas realizadas, os valores de Tmin e Tmáx foram estatisticamente diferentes para os dois tratamentos a nível de $\alpha=0,01$. Os valores de Tgmáx em T1 com Tgmáx em T2 e UR média para T1 e T2, foram diferentes dentro

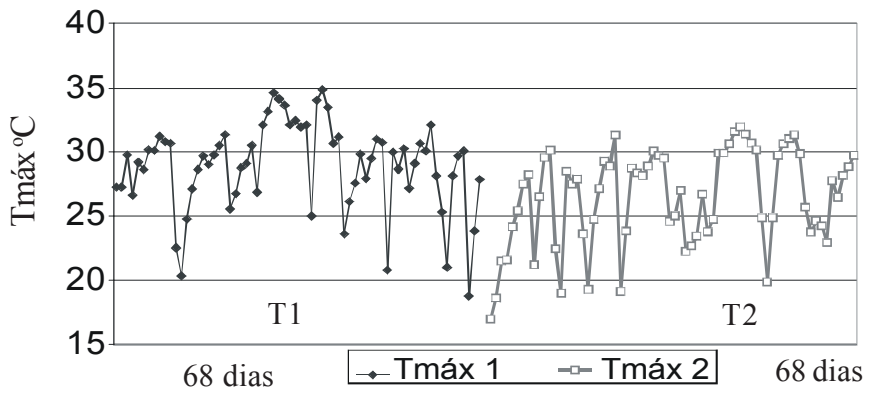

Figura 2. Temperatura máxima (Tmáx), em ${ }^{\circ} \mathrm{C}$, para os tratamentos T1(sem climatização) e T2 (com climatização) ao longo do período estudado dos períodos, pois se rejeitou a hipótese de serem iguais a nível de $\alpha=0,05$.

As temperaturas máximas e mínimas para o tratamento com climatização, estão dentro do limite indicado, conforme os resultados do trabalho de Müller (1982) o qual afirma que, quando a temperatura ultrapassa o valor de $26,7^{\circ} \mathrm{C}$, ocorre um considerável declínio na produção de leite e o balanço calórico é então prejudicado, assim como o consumo alimentar demonstrando que o ambiente físico é inadequado. Foram comparadas as Tmáx de T1 e Tmáx de T2 equivalentes a 68 dias de experimento em cada um dos períodos e confirmados os melhores valores para T2.

A temperatura de globo máxima (Tgmáx) foi menor para o grupo T2, significando que esses animais estavam sob melhores condições térmicas dentro do ambiente climatizado que o grupo, sem nenhum tipo de climatização. Para Kelly e Bond (1971) a temperatura de globo negro é uma indicação dos efeitos combinados de temperatura do ar, temperatura radiante e velocidade do vento, isto é, representa a exposição a todas as fontes de radiação existentes no ambiente (Figura 3).

A umidade relativa média(UR) para os tratamentos 1 e 2 também foi analisada e está representada na Figura 4.

$\mathrm{Na}$ Figura 4 pode observar-se que a UR média $\mathrm{T} 1$ foi maior que a UR média em T2, sendo registrados valores médios de $61,70 \%$

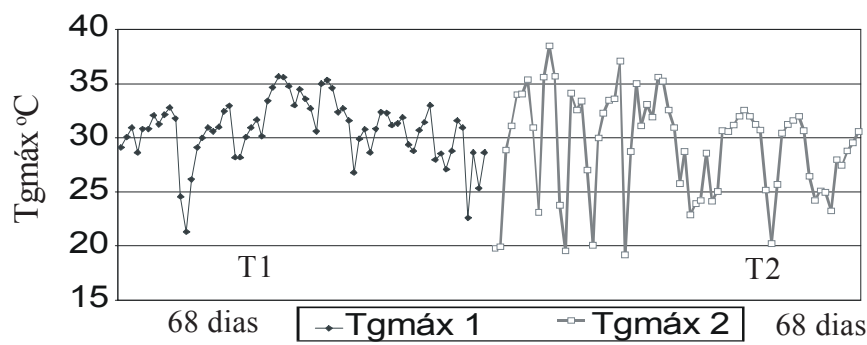

Figura 3. Temperatura de globo máxima (Tgmáx), em ${ }^{\circ} \mathrm{C}$, para os tratamento T1 (sem climatização) e T2 (com climatização) ao longo do período estudado

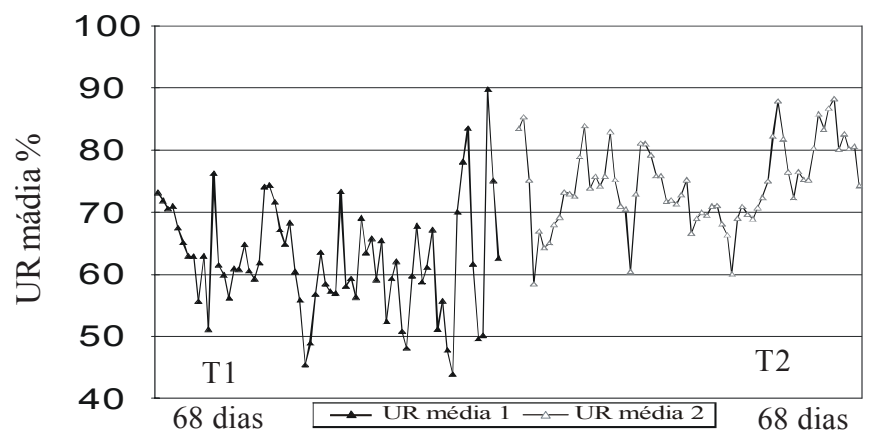

Figura 4. Umidade relativa (UR), em \%, para os tratamentos T1 e T2, ao longo do período estudado

Tabela 1. Valores médios das variáveis utilizadas na caracterização do ambiente térmico nos galpões de 'freestall', sem climatização (T1) e com climatização (T2)

\begin{tabular}{ccccc} 
Ambiente & $\operatorname{Tmin}\left({ }^{\circ} \mathrm{C}\right)$ & Tmáx $\left({ }^{\circ} \mathrm{C}\right)$ & $\operatorname{Tgmáx}\left({ }^{\circ} \mathrm{C}\right)$ & URmédia (\%) \\
\hline T1 (s/climat.) & $19,20 \mathrm{~b}$ & $29,33 \mathrm{~b}$ & $39,79 \mathrm{~A}$ & $61,70 \mathrm{~A}$ \\
$\mathrm{~T} 2$ (c/climat.) & $18,47 \mathrm{a}$ & $26,47 \mathrm{a}$ & $37,77 \mathrm{~B}$ & $65,90 \mathrm{~B}$ \\
\hline
\end{tabular}

a e b: $\alpha=0,01 ; \quad$ A e $B \quad \alpha=0,05$ 
para T1 e 65,90\% para T2, respectivamente. De acordo com as análises, ocorreu diferença estatística entre os dois tratamentos, conforme a Tabela 1. Esta diferença é justificada devido à utilização do equipamento de nebulização, que induz ao acréscimo de vapor d'água no ambiente.

Dos parâmetros avaliados, a produção média de T1 foi mais baixa quando comparada à produção de $\mathrm{T} 2$, sendo portanto significativa essa diferença ao nível de $0,01 \%$. Para a Tmáx 2 e Tgmáx 2 foram diminuindo conforme a produção média de leite (kg/vaca) aumentava. Segundo Damasceno \& Targa (1997) também obtiveram bons resultados de produção de vacas leiteiras sob efeito das condições climáticas, onde afirmam que se houver o conhecimento das relações funcionais existente entre o animal e o meio ambiente irá permitir uma elevação da eficiência produtiva. Já a UR média foi acompanhando o aumento da produção média de leite, mostrando que esta variável não interferiu na produção.

$\mathrm{Na}$ Tabela 2 estão representadas as médias dos índices ITU e ITGU, para os dois tratamentos estudados.

De acordo com os resultados apresentados na Tabela 2, observa-se melhora no ITU do grupo T2, quanto ao conforto

Tabela 2. Médias dos índice de temperatura e umidade (ITU) e índice de temperatura do globo e umidade (ITGU), para os dois tratamentos estudados

\begin{tabular}{ccc}
\hline Ambiente & ITU médio & ITGU médio \\
\hline (sem climatização) T1 & 76 & 79 \\
(com climatização) T2 & 72 & 77 \\
\hline
\end{tabular}

térmico. A maioria dos pontos no gráfico da Figura 5 localizou-se abaixo de 76, onde começa a ser um ponto crítico para o conforto dos animais (Johnson et al. 1963), (Cargill e Stewart, 1966 ; Rosenberg et al., 1983). De acordo com Janini et al., (2002), os valores excedentes a 78 são considerados sob estado de estresse e, neste experimento, encontraram-se valores médios menores para o grupo T2 (72).

Os índices de ITU 2 foram comparados com os índices de ITU externo, do mesmo período do experimento. De acordo com a Figura 6, observa-se que os valores de ITU 2 foram maiores que o ITU externo; mesmo assim, a maioria dos pontos de ITU 2 localizados no gráfico está abaixo de 76, o que vem comprovar a melhoria do ambiente dentro das instalações, cujo fato é devido ao calor latente dos animais.

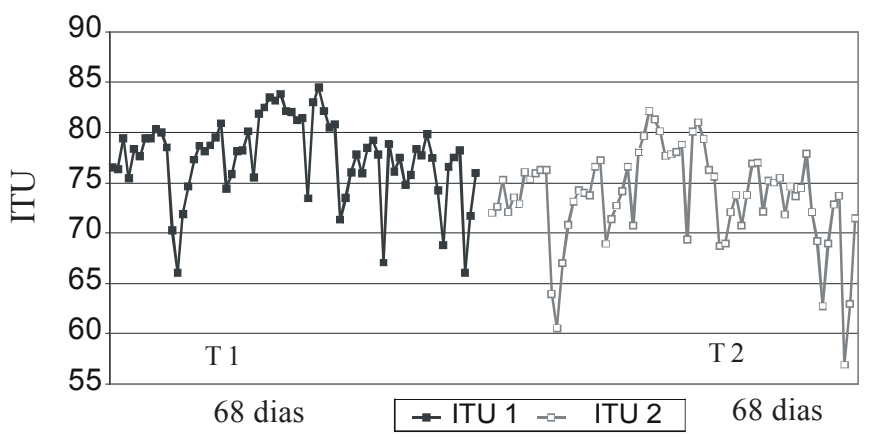

Figura 5. Representação gráfica do índice de temperatura e umidade ITU 1(sem climatização) e ITU 2 (com climatização)

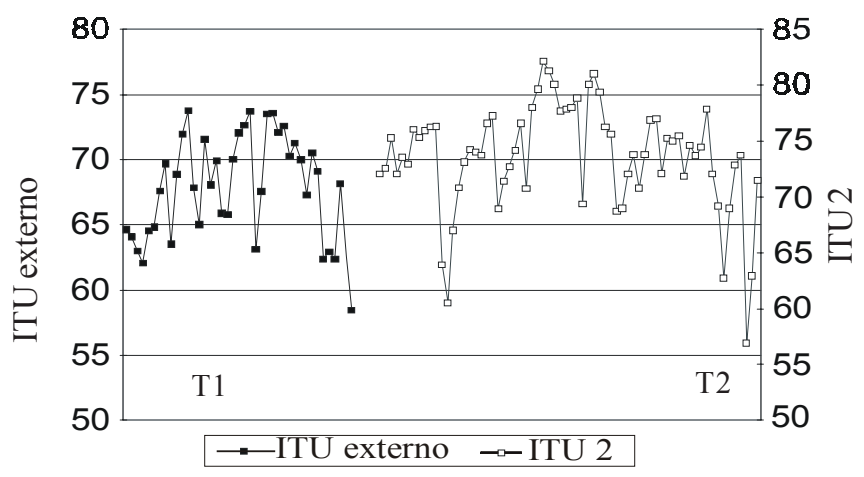

Figura 6. Comparação dos valores de ITU externo com o ITU 2

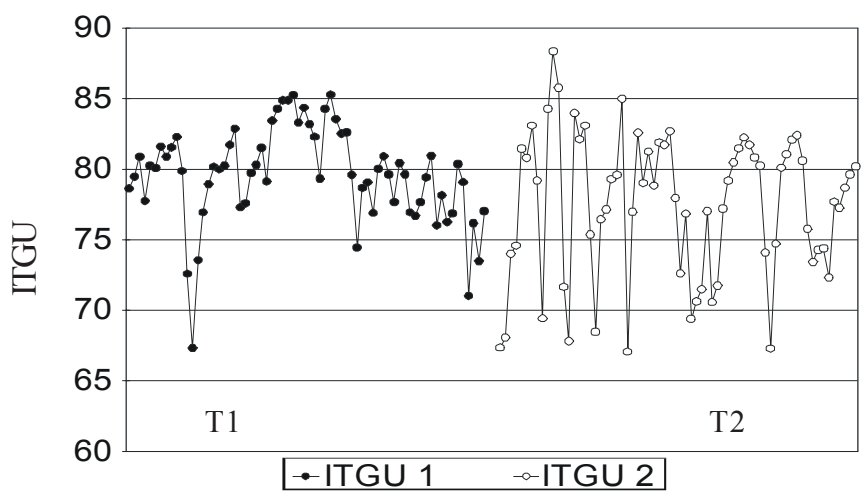

Figura7. Representação gráfica dos índices de temperaatura do globo e umidade ITGU 1 (sem climatização) e ITGU 2 (com climatização)

Foi analisado, também, o índice de ITGU 1 e comparado com ITGU 2 (Figura 7).

Os índices de ITGU do grupo T1 foram maiores que os do grupo T2, conferindo ao T2 melhores condições de conforto para os animais. Campos et al. (2002) encontraram índices de ITGU de 74, 76, 78 e 79 semelhantes a este trabalho, que foi de 77 para o grupo T2 e 79 para o grupo T1. Segundo Baêta e Souza (1997) valor de ITGU de 74 a 78 é considerado um estresse leve; mesmo assim, os resultados finais levaram a se confirmar uma melhora no ambiente dos animais do grupo T2.

Foram analisadas as respostas dos tratamentos comparados à produção média de leite $\left(\mathrm{kg} \mathrm{dia}^{-1} \mathrm{vaca}^{-1}\right)$ para os dois grupos (T1 e T2). Para o grupo T1 a produção média de leite $\left(\mathrm{kg} \mathrm{dia}^{-1} \mathrm{vaca}^{-1}\right)$ foi de 28,50 e, para o grupo T2, foi de 32, 65, ficando evidenciado um acréscimo de 4,2 $\mathrm{kg} \mathrm{dia}^{-1} \mathrm{vaca}^{-1}$.

A Figura 8 mostra que a produção de leite aumentou com um ITU ideal, em que a maioria dos pontos está localizada no gráfico abaixo de 76. Experimentos realizados por Cargill e Stewart (1966) e também por Johnson et al. (1963), indicaram resultados semelhantes aos do grupo T2.

A Figura 9 compara o índice de ITGU com a produção mediana de leite.

O ITGU para o grupo de vacas do T1 foi maior que T2. De acordo com experimentos realizados por Buffington et al.(1981) a produção de leite está inversamente relacionada com o ITGU, ocorrendo o mesmo neste experimento, apesar dos valores terem atingido estresse, considerado leve por Baêta e Souza (1997). 


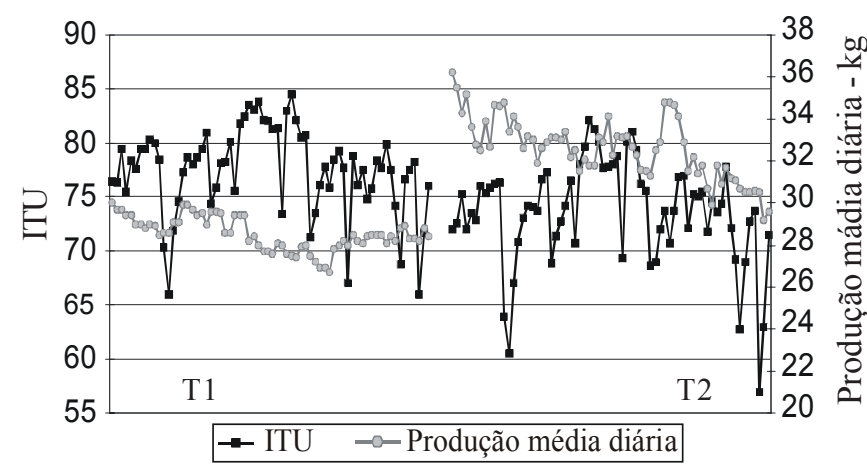

Figura 8. Representação gráfica do índice de ITU e produção de leite diária

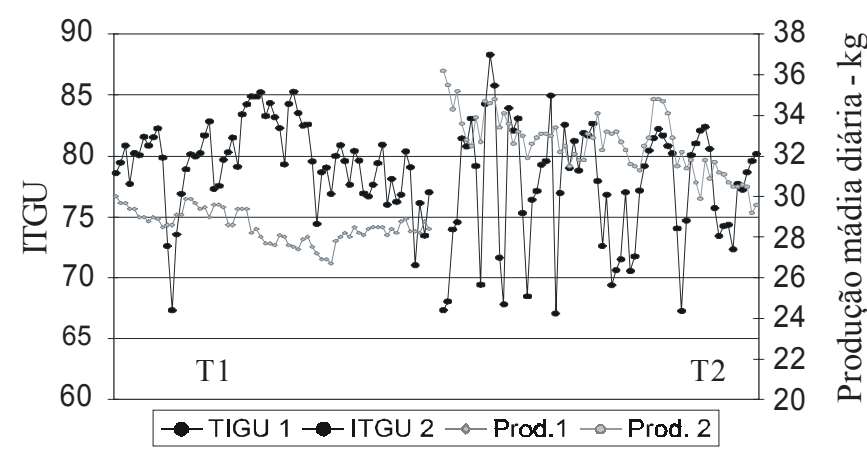

Figura 9. Representação gráfica do índice de ITGU e produção média diária de leite

\section{CONCLUSÕES}

Considerando-se a produção de leite, mesmo com os índices indicando estresse leve ou moderado, os resultados foram satisfatórios para os animais do grupo T2, indicando que a utilização de equipamentos de climatização (ventilação e nebulização) provavelmente trouxe modificações positivas no ambiente físico do 'freestall' estudado.

\section{LITERATURA CITADA}

Arcaro, I, J,. Avaliação da influência de ventilação e aspersão em coberturas de sombrite para vacas em lactação . Campinas, UNICAMP, 2000, 81p. Tese doutorado

Baccari, F:, JR., Johnson, H. D.; Hanh, G. L. Environmental heat effects on growth, plasma $t$, and postheat compensatory effects on Holstein calves. Proceeding. Society of Experimental Biology and Medicine, v.173, p 312-318, 1983.
Baêta, F. C; e Souza, C. F. Ambiência em edificações rurais conforto animal. Viçosa, UFV, 1997, 246p.

Buffington, D.E.; Collazo Arocho, A.; Canton, G.H. Pitt, D. Black globe humidity index (BGHI) as a comfort equation for dairy cows. Trans. ASAE, St. Joseph, v.24, n. 3, p. 711-714, 1981.

Campos, A. T.; Klosowski, E. S.; Santos, W. B. R.; Gasparino, E. Distribuição de temperatura no sentido transversal em um galpão de confinamento Freestall orientado na direção nortesul. In: Congresso Brasileiro de Engenharia Agrícola, 31, 2002. Salvador: SBEA 2002, p. 82.

Cargill, B.F. e Stewart, R.E. Effect of humidity on total heat and total vapor dissipation of holstein cows. Transaction of the ASAE, St. Joseph, v. 9, n.5, p.702-707, 1966.

Damasceno, J. C., Targa, L. A. Definição de variáveis climáticas na determinação da resposta de vacas holandesa em sistema freestall. Energia na Agricultura, Botucatu, v.12, n.2, p.12-25, 1997.

IBGE. Anuário estatísitco. 2001. http://www.ibge.gov.br

Janini, K.; Jacobson, L.; Johnson, V. Ventilating systems for enhancing indoor environmental quality. Biosystems and Agricultural Engineering. 2000 [on line: 28. 05. 2002] acesso: http://www.bae.umn.edu/annrpt/2000/research/ livestock8.html.

Johnson, H.D.; Ragsdale, A.C.; Berry, I.L.; Shanklin, M.D. Effect of various temperature - humidity combinations on milk production of holstein cattle. Columbia: Missouri Agricultural Experiment Station Research Bulletin. p.791, 1963.

Kelly, C. F.; Bond, T. E. Bioclimatic factors and their mesurement. A guide to environmental research on animals. Washington: National Academy of Sciences. 1971.

Müller, P.B. Bioclimatologia aplicada aos animais domésticos. 2.ed. Porto Alegre: Sulina, 1982. 158p.

Rosenberg, L. J.; Biad, B. L.; Verns, S. B. Human and animal biometeorology. In: Microclimate, the biological environment. New York: Wiley- Interscience Publication, 1983. p.423-467.

Titto, E.A.L. Clima: influência na produção de leite. In: Silva, I. J. O. Ambiência na produção de leite. Piracicaba: ESALQ-FEALQ, 1998.p.10-23.

Vilela. D. Leite: Bom para a saúde e melhor ainda para a economia brasileira. Embrapa Gado de Leite-Eventos.p 1-3. 2002. [on line, 05/07/2002]. Acesso. htt://www.cnpgl.embrapa.br/ artigos/leite.html 